\title{
Association between uncooperativeness and the glucose metabolism of patients with chronic behavioral disorders after severe traumatic brain injury: a cross- sectional retrospective study
}

Tomohiro Yamaki ${ }^{1,2^{*}}$, Kosuke Suzuki $^{3}$, Yusuke Sudo $^{3}$, Tomihisa Niitsu $^{3}$, Masahiko Okai ${ }^{2}$, Nobuo Oka ${ }^{2}$ and Masaru Odaki ${ }^{1}$

\begin{abstract}
Bakground: Patients with behavioral disorders following severe traumatic brain injury (sTBI) often have disorders of consciousness that make expressing their emotional distress difficult. However, no standard method for assessing the unsettled and unforeseen responses that are associated with behavioral disorders has yet to be established. Because the thalamus is known to play a role in maintaining consciousness and cognition, we used $18 \mathrm{~F}-$ fluorodeoxyglucose positron emission tomography/computed tomography (18F-FDG-PET/CT) to examine the association between brain glucose metabolism in the thalamus and behavioral disorders.

Methods: We retrospectively analyzed 70 consecutive patients with sTBI who had been involved in motor vehicle accidents. To assess behavioral disorders, we evaluated 18 symptoms using the Brief Psychiatric Rating Scale (BPRS): Emotional Withdrawal, Conceptual Disorganization, Tension, Mannerisms and Posturing, Motor Retardation, Uncooperativeness, Blunted Affect, Excitement, Somatic Concern, Anxiety, Feeling of Guilt, Grandiosity, Depressive Mood, Hostility, Suspiciousness, Hallucinatory Behavior, Unusual Thought Content, and Disorientation. First, we identified clinical characteristics of sTBI patients with behavioral disorders. Next, we retrospectively analyzed 18F-FDG-PET/ $C T$ data to assess how thalamic activity was related with abnormal behaviors.

Results: Twenty-six patients possessed the minimum communicatory ability required for psychiatric interview. Among them, 15 patients (57.7\%) were diagnosed with behavioral disorder, 14 of whom had reached a stable psychiatric state after about 426.6 days of treatment. Excitement (13 patients) and uncooperativeness (10 patients) were the most frequently observed symptoms. Available 18F-FDG-PET/CT data indicated that thalamic glucose metabolism was imbalanced and lateralized $(p=0.04)$ in 6 patients who exhibited uncooperativeness.

(Continued on next page)
\end{abstract}

\footnotetext{
* Correspondence: t-yamaki@chiba-ryougo.jp

'Division of Neurosurgery, Chiba Ryogo Center, National Agency for Automotive Safety and Victims' Aid, 3-30-1 Isobe, Mihama-ku, Chiba 261-0012, Japan

2Division of PET imaging, Chiba Ryogo Center, National Agency for

Automotive Safety and Victims' Aid, Chiba, Japan

Full list of author information is available at the end of the article
}

(c) The Author(s). 2018 Open Access This article is distributed under the terms of the Creative Commons Attribution 4.0 International License (http://creativecommons.org/licenses/by/4.0/), which permits unrestricted use, distribution, and reproduction in any medium, provided you give appropriate credit to the original author(s) and the source, provide a link to the Creative Commons license, and indicate if changes were made. The Creative Commons Public Domain Dedication waiver (http://creativecommons.org/publicdomain/zero/1.0/) applies to the data made available in this article, unless otherwise stated. 


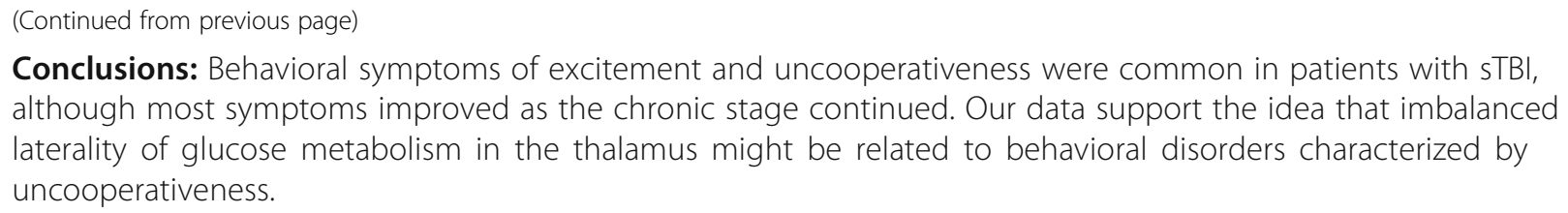

Conclusions: Behavioral symptoms of excitement and uncooperativeness were common in patients with sTBI, although most symptoms improved as the chronic stage continued. Our data support the idea that imbalanced laterality of glucose metabolism in the thalamus might be related to behavioral disorders characterized by uncooperativeness.

Trial registration: UMIN 000029531. Registered 27 March 2017, retrospectively registered.

Keywords: Behavioral disorder, 18F-FDG-PET, Traumatic brain injury

\section{Background}

In the chronic stage of severe traumatic brain injury (sTBI), patients can recover from disorders of consciousness including unresponsive wakefulness syndrome (vegetative state; patients awake from coma but remain unresponsive) and minimally consciousness state [1-4]. However, the chronic stage of neurorehabilitation is often accompanied by behavioral disorders, while the arousal sate and neurological status are typically unstable [1-8]. Most patients with sTBI have difficulty expressing their emotional distress because of disorders of consciousness, disrupted higher brain function, and verbal disturbance such as tracheostomy [9-13]. However, for patients who can communicate at some basic level, emotional explosions and abnormal behaviors are often observed as nonverbal responses over the clinical course following neurorehabilitation $[9,10,14-16]$. Consequently, therapists and caregivers are adversely affected by this unsettling patient behavior that is based on insufficient communication $[1,2,8-10,16]$.

Recently, the thalamus was shown to play a role in cognition, the maintenance of consciousness, and the modulation of arousal and alertness [17-19]. In this study, we searched for clinical features common to patients with sTBI who exhibit behavioral disorders to determine if abnormal thalamic activity is associated with behavioral disorders. We assessed thalamic activity as glucose metabolism, objectively measured by18F-fluorodeoxyglucose positron emission tomography/computed tomography (18F-FDG-PET/CT).

The Brief Psychiatric Rating Scale (BPRS) assesses a large number of behaviors including (1) Emotional Withdrawal, (2) Conceptual Disorganization, (3) Tension, (4) Mannerisms and Posturing, (5) Motor Retardation, (6) Uncooperativeness, (7) Blunted Affect, (8) Excitement, (9) Somatic Concern, (10) Anxiety, (11) Feelings of Guilt, (12) Grandiosity, (13) Depressive Mood, (14) Hostility, (15) Suspiciousness, (16) Hallucinatory Behavior, (17) Unusual Thought Content, and (18) Disorientation. Rating of these 18 symptoms presents a quantitative measure of the overall mental status and degree of abnormal behavior [20].

\section{Methods}

\section{Study design}

This was a retrospective, single institutional study of inpatients with sTBI from June 2013 to July 2017.
Informed consent to use medical records and images were obtained from the patients' legal representatives. The study was conducted after approval by the institutional ethics committee (2017-14). A website with additional information and an opt-out option was set up and patients' legal representatives were informed (http://www.chiba-ryougo.jp/publics/index/194/).

\section{Patients}

Seventy-three patients with sTBI were enrolled. All patients had a Glasgow Coma Scale (GCS) score of $\leq 8$ at the time of their accident and severe verbal disturbance due to aphasia, mutism, tracheostomy, dysthymia, communication disorder, or voice disturbance. This study excluded patients with a history of psychiatric disorders.

\section{Clinical assessment}

Clinical assessments were performed by neurosurgeons and psychiatrists. The Coma Recovery Scale-Revised (CRS-R) and BPRS-based classification were used to assess clinical manifestation [20, 21]. The original BPRS includes 18 items scored from 0 (absent) to 7 (extremely severe); however, rather than using the 8-point-scale, we only judged whether or not a patient exhibited each symptom, as has been described previously [20, 22-24].

We divided BPRS-based classification into a verbal communication domain and non-verbal communication categories. The non-verbal communication category included eight BPRS symptoms (Emotional Withdrawal, Conceptual Disorganization, Tension, Mannerisms and Posturing, Motor Retardation, Uncooperativeness, Blunted Affect, and Excitement) and the verbal category contained the other 10 symptoms (Somatic Concern, Anxiety, Feelings of Guilt, Grandiosity, Depressive Mood, Hostility, Suspiciousness, Hallucinatory Behavior, Unusual Thought Content, and Disorientation) When we could not definitively determine if a patient exhibited a particular symptom, the item was regarded as negative because of disorders of consciousness, disrupted higher brain function, or verbal disturbance that precluded patients from explicitly expressing the condition. Psychiatrists interviewed the patients once a week during hospitalization, and the BPRS-based assessment was conducted at the first psychiatric interview. 
We determined the time between onset and remission of behavioral disorders using the date of the first psychiatrist intervention as the starting point and the date that the psychiatrist noted "stable" in the medical record as the end point. BPRS and CRS-R scores were used at the same time on medical records.

\section{F-FDG-pet/CT}

The exclusion criteria for 18F-FDG-PET/CT imaging were as follows: symptomatic status epilepticus, medical instability, uncooperative behavior or poor glycemic control. Patients were intravenously injected with $350 \mathrm{MBq}$ of 18F-FDG following a period of at least $7 \mathrm{~h}$ of fasting. Image acquisition (Discovery ${ }^{\circ} \mathrm{ST}-\mathrm{E}$ PET/CT, GE Healthcare, Tokyo, Japan) was then performed after $60 \mathrm{~min}$.

The primary objective was to measure the maximum standardized uptake value (SUVmax) of the whole brain, each hemisphere, and the thalamus using threedimensional volumes of interest (VOIs) based on commercial software (syngo.via ${ }^{\oplus}$, Siemens, Tokyo, Japan). VOIs were set at $50 \%$ of the peak SUV value (Additional file 1: Figure S1).

\section{Statistical analyses}

Statistical analyses were performed using JMP $10^{\circ}$ statistical software (IBM Japan, Tokyo, Japan). Statistical significance was calculated using Fisher's exact tests, Chi-squared tests, and Student $t$ tests. We did not correct for multiple comparison because we a priori focused on thalamic function. Data are presented as the mean \pm standard deviation (SD). Results were considered statistically significant if the $p$-value was less than 0.05 .

\section{Result}

\section{Clinical symptoms}

Three patients with a history of a psychiatric disorder were excluded (Fig. 1). The mean time between the accident and admission to the hospital was 623 days. Clinical manifestations included severe disability in 27 patients (CRS-R score 19.6), minimally consciousness state in 13 (CRS-R score 14.1), and unresponsive wakefulness syndrome in 30 (CRS-R score 4.5; $p<0.0001$ ).

Of the 70 enrolled patients, 44 presented with poor wakefulness, consciousness, or linguistic ability, which made psychiatric assessment impossible. Clinical manifestations in the remaining 26 patients were less severe, and they possessed at least the minimum level of communicative ability that allowed psychiatric assessment (Additional file 2: Table S1). Of these 26 patients, 15 patients $(57.7 \%)$ were diagnosed with behavioral disorders (BD group) while the remaining 11 (42.3\%) were not (Non-BD group). Neither the total CRS-R nor the subscale scores significantly differed between the BD group and the Non-BD group (Table 1).

In the BD group, Excitement (86.7\%) and Uncooperativeness (60\%) were well observed as representative symptoms. We found no significant differences in age, sex, or auditory, visual, motor, oromotor/verbal, or arousal-related neurological functions between the BD and Non-BD groups. As shown in Fig. 2 and Tables 2, 14 members $(93.3 \%)$ of the BD group reached a psychiatrically stable state after treatment, with the mean latency for psychiatric stability (starting from the beginning of psychiatric treatment) $426.6 \pm 342.3$ days. Psychiatric treatments for BD patients with psychiatric

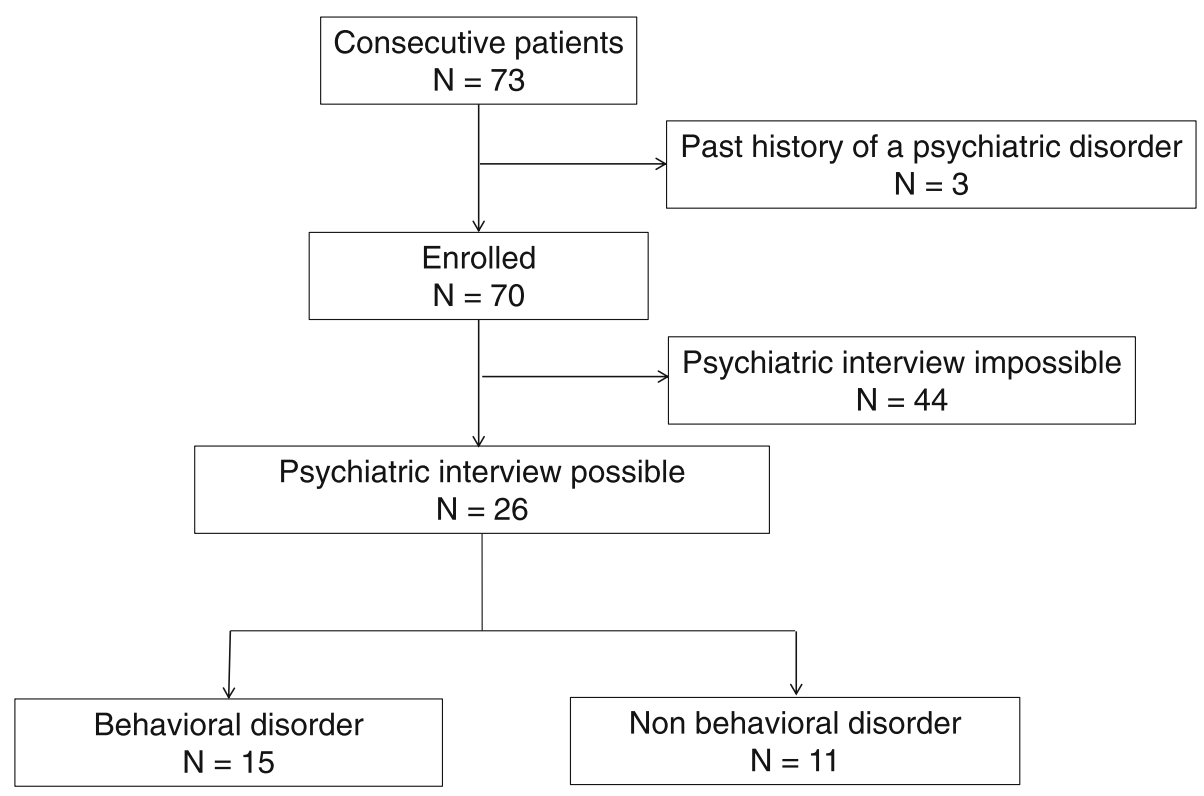

Fig. 1 Study design and analysis profile. Psychiatric interview and behavioral disorders 
Table 1 Comparison of severe traumatic brain injury patients with and without behavioral disorders

\begin{tabular}{|c|c|c|c|}
\hline Demographic and clinical data & sTBI with behavioral disorder $(n=15)$ & sTBI without behavioral disorder $(n=11)$ & $P$ \\
\hline Age (year), mean (SD) & $46.7(12.3)$ & $49.5(21.9)$ & 0.67 \\
\hline Male, n (\%) & $12(80)$ & $8(72.7)$ & 1 \\
\hline The sum of CRS-R at admission, mean (SD) & $20.3(3.0)$ & $18.8(2.7)$ & 0.21 \\
\hline Auditory function score, mean (SD) & $3.4(0.1)$ & $3.3(0.9)$ & 0.61 \\
\hline Visual function score, mean (SD) & $4.5(1.3)$ & $4.3(1.5)$ & 0.72 \\
\hline Motor function score, mean (SD) & $5.6(0.6)$ & $5.3(0.9)$ & 0.29 \\
\hline Oromotor/verbal function score, mean (SD) & $2.3(0.8)$ & $1.8(0.9)$ & 0.14 \\
\hline Communication score, mean (SD) & $1.4(0.6)$ & $1.2(0.6)$ & 0.38 \\
\hline Arousal score, mean (SD) & $3.0(0)$ & $3.0(0)$ & ND \\
\hline \multicolumn{4}{|l|}{ Symptoms of behavioural disorder } \\
\hline Somatic concern, n (\%) & $3(20)$ & $0(0)$ & 0.24 \\
\hline Anxiety, n (\%) & $2(13.3)$ & $0(0)$ & 0.49 \\
\hline Emotional withdrawal, n (\%) & $2(13.3)$ & $0(0)$ & 0.49 \\
\hline Conceptual disorganization, n (\%) & $1(6.7)$ & $0(0)$ & 1.00 \\
\hline Feelings of guilt, $n(\%)$ & $0(0)$ & $1(9.1)$ & 0.42 \\
\hline Tension, n (\%) & $0(0)$ & $0(0)$ & ND \\
\hline Mannerisms and posturing, n (\%) & $5(33.3)$ & $0(0)$ & 0.05 \\
\hline Grandiosity, n (\%) & $0(0)$ & $0(0)$ & ND \\
\hline Depressive mood, n (\%) & $4(26.7)$ & $0(0)$ & 0.11 \\
\hline Hostility, n (\%) & $5(33.3)$ & $0(0)$ & 0.05 \\
\hline Suspiciousness, n (\%) & $1(6.7)$ & $0(0)$ & 1.00 \\
\hline Hallucinatory behaviour, n (\%) & $3(20)$ & $0(0)$ & 0.24 \\
\hline Motor retardation, n (\%) & $3(20)$ & $0(0)$ & 0.24 \\
\hline Uncooperativeness, n (\%) & $10(66.7)$ & $1(9.1)$ & $0.005^{*}$ \\
\hline Unusual thought content, n (\%) & $2(13.3)$ & $0(0)$ & 0.49 \\
\hline Blunted affect, n (\%) & $4(26.7)$ & $0(0)$ & 0.11 \\
\hline Excitement, n (\%) & $13(86.7)$ & $1(9.1)$ & $0.002^{*}$ \\
\hline Disorientation, n (\%) & $5(33.3)$ & $0(0)$ & 0.05 \\
\hline
\end{tabular}

${ }^{*} P<0.05 ; C R S-R$, Coma Recovery Scale-Revised; ND, not detected; $S D$, standard deviation; STBI, severe traumatic brain injury.

stability included sodium valproate $(n=7)$, quetiapine fumarate $(n=7)$, and aripiprazole $(n=4)$.

\section{F-FDG-pet/CT}

To find the thalamic activity patterns that were characteristics of behavioral disorders, we measured the SUVmax of the thalamus with 18F-FDG-PET/CT. Scanning image data were available for 14 patients (Table 3 , Additional file 3 : Table S2, Additional file 4: Figure S2). To take the side of injury into account, we calculated the laterality ratio of SUVmax for the left and right regions as LR ratio = SUV$\max _{\text {left }} /$ SUVmax $x_{\text {right }}$.

The sample size was large enough for statistical analyses of SUVmax to be performed for the BPRSclassification categories of Excitement and Uncooperativeness. No significant differences were found between patients who did or did not exhibit Excitement
(Additional file 5: Table S3). However, those who exhibited Uncooperative behavior displayed imbalanced laterality of glucose metabolism in thalamus compared with those who did not $(p=0.04)$.

\section{Discussion}

Here, we show that Excitement and Uncooperativeness are the primary abnormal behaviors in chronic sTBI. 18F-FDG-PET/CT imaging revealed imbalanced laterality of thalamic glucose metabolism in those who were Uncooperative, pointing to a role for the thalamus in pathologically Uncooperative behavior.

To date, behavioral disorders in sTBI and mild TBI have been grouped together when discussed [1, 2, 8]. Recently, TBI pathology appears to differ depending on the severity of the brain injury $[1,2,8]$. Indeed, depression and mood disorder are commonly observed in patients 


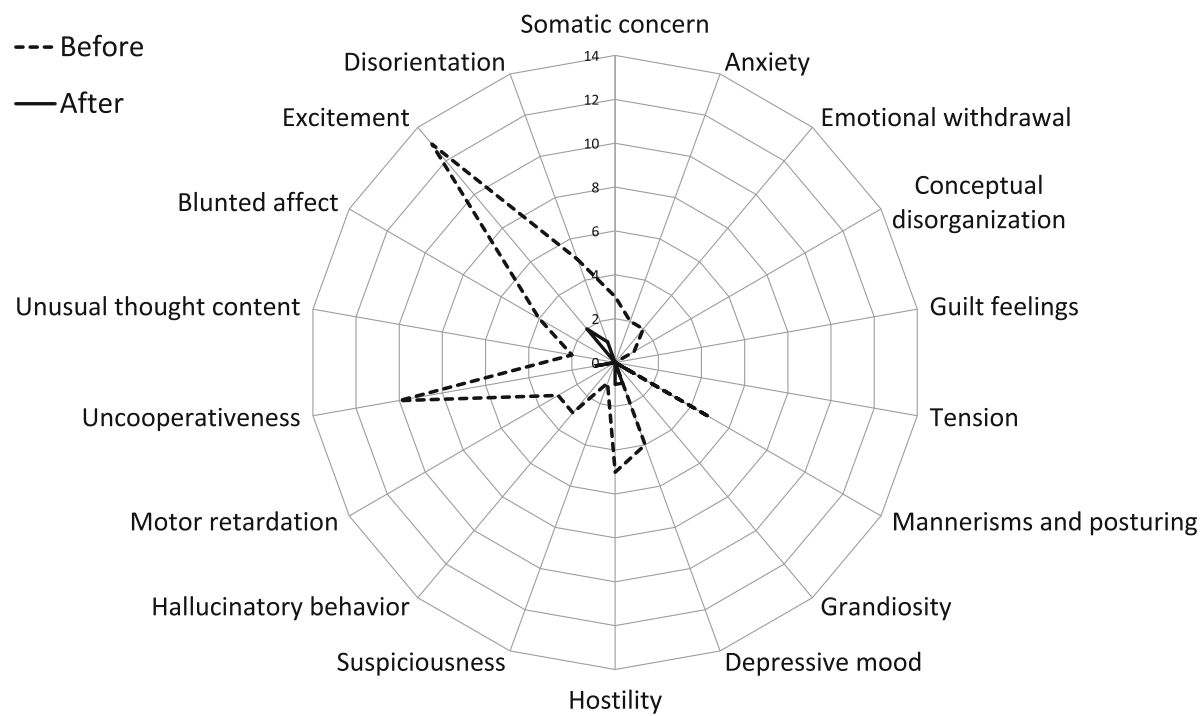

Fig. 2 Total numbers of the abnormal behaviors obtained from 26 patients with severe traumatic brain injury before and after psychiatric intervention. Behaviors are based on Brief Psychiatric Rating Scale classification system

with mild TBI [25]. However, unsettling and unforeseen reactions to therapists and caregivers is a common occurrence during neurorehabilitation for patients with sTBI $[6,7,9,10,12,26-29]$. Therefore, neurological assessment and psychiatric assessment have not been able to segregate patients for managing treatment.

Although the CRS-R scale is widely used to assess clinical manifestations in patients with sTBI, it is not sufficient for appropriate mental and behavioral assessment $[3,21,23]$. This is because factors such as tracheotomy, the impairment of verbal function, aphasia and fluctuation of awareness, and disrupted higher brain function disturb self-expression in these patients [9-12, 26-29]. Our data show that patients with sTBI have a broad variety of symptoms. In the future, we must

Table 2 Demographic and clinical data of severe traumatic brain injury patients with behavioral disorders

\begin{tabular}{ll}
\hline Demographic and clinical data & $\begin{array}{l}\text { sTBI with behavioral disorder } \\
(n=15)\end{array}$ \\
\hline Representative symptom & $13(86.7)$ \\
Excitement, $\mathrm{n}(\%)$ & $9(60)$ \\
Uncooperativeness, $\mathrm{n}(\%)$ & $14(93.3)$ \\
Psychiatric stable state, $\mathrm{n}(\%)$ & $426.6(342.3)$ \\
The duration until psychiatric stability, & \\
mean (SD) & \\
The kinds of effective psychiatric drugs & \\
Sodium valproate increase or start, $\mathrm{n}(\%)$ & $7(50)$ \\
$\begin{array}{l}\text { Quetiapine fumarate increase of start, } \mathrm{n} \\
\text { (\%) }\end{array}$ & $7(50)$ \\
Aripiprazole start, $\mathrm{n}(\%)$ & $4(28.6)$ \\
\hline
\end{tabular}

$S D$, standard deviation; $S T B I$, severe traumatic brain injury. consider adding nonverbal assessment such as the visual analogue scale and the face-pain scale for detecting posttraumatic agitation, aggression, irritability, and sleep disorders, because these common symptoms are not included in the BPRS-based classification $[10,16$, 28-31].

To assess their emotional distress, we chose a nonverbal, objective image analysis of the thalamus. 18F-FDG-PET/ CT has been established as a useful technique [32-35], with one study showing that cortico-thalamo-cortical glucose metabolism was related to brain dysfunction in patients with sTBI [36]. Additionally, the thalamus is known to have a major role in cognitive function, maintenance of wakeful states, and neuroplasticity [17-19, 37, 38]. Our data showed imbalanced glucose metabolism in the thalamus of the patients who displayed Uncooperativeness. Glucose metabolism in the left thalamus was lower than in the right for Uncooperative patients. This might be related to language function, which is typically left-dominant [39]. Further, the imbalanced metabolism in the thalamus might influence Papez' or Yakovlev' limbic connection related to emotional control, resulting in uncooperativeness behavior following neurorehabilitation [38-43]. Importantly, most patients' behavioral disorders improved to some extent after psychiatric treatment during the clinical course. Based on our data, sodium valproate and quetiapine fumarate have the potential to be effective therapeutic drugs for these behavioral disorders. These drugs might have an influence on FDG uptake because some psychotropic agents can change glucose metabolism in some brain areas [44-46]. We will soon begin designing a prospective trial using 18F-FDG-PET/CT to determine if these drugs can improve the imbalance in brain-glucose metabolism. 
Table 3 Comparison of severe traumatic brain injury (STBI) patients with and without symptoms of uncooperativeness in right hemisphere, left hemisphere, right thalamus, left thalamus, the laterality ratio of SUVmax for the left and right regions as LR ratio $=$ SUVmax Ieft $_{\text {SUVmax }}$ right of hemisphere, and thalamus by glucose uptake based on 18F-fluorodeoxyglucose positron emission tomography/computed tomography

\begin{tabular}{|c|c|c|c|}
\hline & SUVmax \pm SD $(95 \% \mathrm{Cl})$ & & \\
\hline Target of VOls & sTBI with Uncooperativeness $n=6$ & sTBI without Uncooperativeness $n=8$ & $P$ \\
\hline Whole brain & $11.94 \pm 3.4(8.37--15.51)$ & $11.53 \pm 3.3(8.77--14.28)$ & 0.82 \\
\hline Right hemisphere & $12.17 \pm 3.83(8.15--16.19)$ & $12.24 \pm 4.6(8.39--16.09)$ & 0.98 \\
\hline Left hemisphere & $10.89 \pm 2.98(7.76--14)$ & $11.33 \pm 4.58(7.5--15.16)$ & 0.84 \\
\hline LR ratio of hemisphere & $0.91 \pm 0.11(0.8--1.02)$ & $0.93 \pm 0.09(0.85--1)$ & 0.73 \\
\hline Right thalamus & $8.23 \pm 2.57(5.53--10.93)$ & $6.76 \pm 1.73(5.32--8.21)$ & 0.23 \\
\hline Left thalamus & $6.04 \pm 2.28(3.64--8.44)$ & $7.25 \pm 2.59(5.09--9.41)$ & 0.38 \\
\hline LR ratio of thalamus & $0.75 \pm 0.11(0.51--0.99)$ & $1.09 \pm 0.1(0.88--1.3)$ & $0.04^{*}$ \\
\hline
\end{tabular}

${ }^{*} P<0.05 ; C l$, confidence interval; LR ratio, SUVmax left / SUVmax right; SD, standard deviation; sTBI, severe traumatic brain injury; SUVmax, maximum standardized uptake value; $\mathrm{VOI}$, volume of interest

A major limitation of the present study is the probability of false positive findings due to the small sample size. A small sample was unavoidable because patients with behavioral disorders did not always cooperate with medical treatment, continuous rehabilitation, or image acquisition. An appropriate psychiatric approach that includes drugs and assessment will need more detailed information and require further investigation in a large sample.

\section{Conclusion}

We found that Excitement and Uncooperativeness were the most commonly observed abnormal behaviors in patients with sTBI over the course of rehabilitation and care. Most abnormal behaviors improved over time. 18F-FDG-PET/CT images revealed imbalanced laterality of glucose metabolism in the thalamus of pathologically Uncooperative patients with sTBI.

\section{Additional files}

Additional file 1: Figure S1. Representative images of a three-dimensional volume of interest measurement (a) and color mapped image (b) of glucose metabolism measured via 18F-fluorodeoxyglucose positron emission tomography/computed tomography. (PPTX $380 \mathrm{~kb}$ )

Additional file 2: Table S1. Comparison between the patients who were evaluated for psychiatric assessment (the evaluable group) and those who could not be assessed (the unevaluable group). (DOCX $18 \mathrm{~kb}$ )

Additional file 3: Table S2. Clinical information for 14 patients who had severe traumatic brain injury and provided $18 \mathrm{~F}$-fluorodeoxyglucose positron emission tomography/computed tomography images. Patients are separated based on whether or not they were diagnosed with a behavioral disorder. (XLSX $10 \mathrm{~kb}$ )

Additional file 4: Figure S2. All available 18F-fluorodeoxyglucose positron emission tomography/computed tomography images for the 14 patients who had severe traumatic brain injury with or without a behavioral disorder. (PPTX 885 kb)

Additional file 5: Table S3. Comparison of glucose uptake in patients who had severe traumatic brain injury, with or without non-verbal symptoms defined by the Brief Psychiatric Rating Scale classification system (Anxiety, Feelings of Guilt, Mannerisms and Posturing, Depressive Mood, Hostility,
Hallucinatory Behavior, Motor Retardation, Blunted Affect, Excitement). Data are presented for the right hemisphere, left hemisphere, right thalamus, left thalamus, hemispheric LR ratio, and thalamic LR ratio. Glucose uptake is based on 18F-fluorodeoxyglucose positron emission tomography/computed tomography. ${ }^{*} P<0.05, C l$, confidence interval; $L R$ ratio, laterality ratio of SUVmax for the left and right regions; $S D$, standard deviation; STBI, severe traumatic brain injury; SUVmax, maximum standardized uptake value; VOI, volume of interest. (XLSX $16 \mathrm{~kb})$

\section{Abbreviations}

18F-FDG-PET/CT: 18F-fluorodeoxyglucose positron emission tomography/ computed tomography; BD: Behavioral disorder; BPRS: Brief Psychiatric Rating Scale; CRS-R: Coma Recovery Scale-Revised; GCS: Glasgow Coma Scale; LR ratio: Laterality ratio of SUVmax for the left and right regions; SD: Standard deviation; STBI: Severe traumatic brain injury; SUVmax: Maximum standardized uptake value; VOls: Volumes of interest

\section{Acknowledgements}

We wish to thank Prof. lyo in Chiba University hospital for helping us. We would also like to thank Adam Phillips, PhD, from Edanz Group (www.edanzediting.com/ac) for editing a draft of this manuscript.

\section{Fundings}

The authors have no funding to declare.

\section{Availability of data and materials}

The datasets generated during and/or analyzed during the current study are not publicly available due to our institutional protocol but are available from the corresponding author on reasonable request.

\section{Authors' contributions}

TY conceived of the study and participated in its design, coordination, acquisition, analysis, and interpretation of data. KS and YS conceived of the study and participated in its design and acquisition of data. TN performed critical revision of manuscript for important intellectual content. MOkai, $\mathrm{NO}$,and MOdaki participated in data acquisition and helped draft the manuscript. All authors read and approved the final manuscript.

\section{Ethics approval and consent to participate}

Informed consent for the use of medical records and images were obtained from the patients' legal representatives. The study was conducted after approval by the institutional ethics committee (2017-14).

\section{Consent for publication}

This manuscript does not contain any individual person's data. 


\section{Competing interests}

The authors have no competing interest to declare.

\section{Publisher's Note}

Springer Nature remains neutral with regard to jurisdictional claims in published maps and institutional affiliations.

\section{Author details}

${ }^{1}$ Division of Neurosurgery, Chiba Ryogo Center, National Agency for Automotive Safety and Victims' Aid, 3-30-1 Isobe, Mihama-ku, Chiba 261-0012, Japan. 2Division of PET imaging, Chiba Ryogo Center, National Agency for Automotive Safety and Victims' Aid, Chiba, Japan. ${ }^{3}$ Department of Psychiatry, Graduate School of Medicine, Chiba University, Chiba, Japan.

Received: 24 January 2018 Accepted: 17 April 2018

Published online: 23 April 2018

\section{References}

1. Stéfan A, Mathé JF. SOFMER group. What are the disruptive symptoms of behavioral disorders after traumatic brain injury? A systematic review leading to recommendations for good practices. Ann Phys Rehabil Med. 2016:59:5-17. https://doi.org/10.1016/j.rehab.2015.11.002.

2. Wheeler S, Acord-Vira A, Davis D. Effectiveness of interventions to improve occupational performance for people with psychosocial, behavioral, and emotional impairments after brain injury: a systematic review. Am J Occup Ther. 2016;70:7003180060p1-9. https://doi.org/10.5014/ajot.115.020677.

3. Giacino JT, Schnakers C, Rodriguez-Moreno D, Kalmar K, Schiff N, Hirsch J. Behavioral assessment in patients with disorders of consciousness: gold standard or fool's gold? Prog Brain Res. 2009;177:33-48. https://doi.org/10. 1016/S0079-6123(09)17704-X

4. Laureys S, Celesia GG, Cohadon F, Lavrijsen J, León-Carrión J, Sannita WG, et al. Unresponsive wakefulness syndrome: a new name for the vegetative state or apallic syndrome. BMC Med. 2010;8:68. https://doi.org/10.1186/ 1741-7015-8-68

5. Schnakers C, Monti MM. Disorders of consciousness after severe brain injury: therapeutic options. Curr Opin Neurol. 2017;30:573-9. https://doi.org/10. 1097/WCO.0000000000000495.

6. Hammond FM, Hart T, Bushnik T, Corrigan JD, Sasser H. Change and predictors of change in communication, cognition, and social function between 1 and 5 years after traumatic brain injury. J Head Trauma Rehabil. 2004;19:314-28.

7. Pignat JM, Jöhr J, Diserens K. From disorders of consciousness to early neurorehabilitation using assistive technologies in patients with severe brain damage. Curr Opin Neurol. 2015;28:587-94. https://doi.org/10.1097/ WCO.0000000000000264

8. Wilson L, Stewart W, Dams-O'Connor K, Diaz-Arrastia R, Horton L, Menon DK, et al. The chronic and evolving neurological consequences of traumatic brain injury. Lancet Neurol. 2017;16:813-25. https://doi.org/10.1016/S14744422(17)30279-X

9. Vas AK, Chapman SB, Cook LG. Language impairments in traumatic brain injury: a window into complex cognitive performance. Handb Clin Neurol. 2015;128:497-510. https://doi.org/10.1016/B978-0-444-63521-1.00031-5.

10. James Al, Böhnke JR, Young AW, Lewis GJ. Modelling verbal aggression, physical aggression and inappropriate sexual behaviour after acquired brain injury. Proc Biol Sci. 2015;282 https://doi.org/10.1098/rspb.2015.0711.

11. Humble SS, Wilson LD, McKenna JW, Leath TC, Song Y, Davidson MA, et al. Tracheostomy risk factors and outcomes after severe traumatic brain injury. Brain Inj. 2016;30:1642-7.

12. Brassel S, Kenny B, Power E, Elbourn E, McDonald S, Tate R, et al. Conversational topics discussed by individuals with severe traumatic brain injury and their communication partners during sub-acute recovery. Brain Inj. 2016;30:1329-42

13. Max JE, Robin DA, Lindgren SD, Smith WL Jr, Sato Y, Mattheis PJ, et al. Traumatic brain injury in children and adolescents : psychiatric disorders ar one year. J Neuropsychiatry Clin Neurosci. 1998;10:290-7.

14. Plantier D, Luauté J. SOFMER group. Drugs for behavior disorders after traumatic brain injury: systematic review and expert consensus leading to French recommendations for good practice. Ann Phys Rehabil Med. 2016; 59:42-57. https://doi.org/10.1016/j.rehab.2015.10.003.
15. Wong CG, Rapport LJ, Meachen SJ, Hanks RA, Lumley MA. Behavioral inhibition and activation in traumatic brain injury. Rehabil Psychol. 2016;61: 397-407.

16. Hart T, Brockway JA, Maiuro RD, Vaccaro M, Fann JR, Mellick D, et al. Anger self-management training for chronic moderate to severe traumatic brain injury: results of a randomized controlled trial. J Head Trauma Rehabil. 2017; 32:319-31. https://doi.org/10.1097/HTR.0000000000000316.

17. Laureys S, Faymonville ME, Luxen A, Lamy M, Franck G, Maquet P. Restoration of thalamocortical connectivity after recovery from persistent vegetative state. Lancet. 2000;20(355):1790-1.

18. Schiff ND. Central thalamic contributions to arousal regulation and neurological disorders of consciousness. Ann N Y Acad Sci. 2008;1129:105-18. https://doi.org/10.1196/annals.1417.029.

19. Van der Werf YD, Witter MP, Groenewegen HJ. The intralaminar and midline nuclei of the thalamus. Anatomical and functional evidence for participation in processes of arousal and awareness. Brain Res Brain Res Rev. 2002;39:107-40.

20. Overall JE, Gorham DR. The brief psychiatric rating scale. Psychol Rep. 1962; 10:799-812.

21. Giacino JT, Kalmar K, Whyte J. The JFK coma recovery scale-revised: measurement characteristics and diagnostic utility. Arch Phys Med Rehabil. 2004;85:2020-9.

22. Fairbanks LA, MT MG, Harris CJ. Nonverbal interaction of patients and therapists during psychiatric interviews. J Abnorm Psychol. 1982;91:109-19.

23. Toomey R, Schuldberg D, Corrigan P, Green MF. Nonverbal social perception and symptomatology in schizophrenia. Schizophr Res. 2002; 1(53):83-91.

24. Miyata R, BPRS manual, Japanese (ver.1.1), 2013 [accessed 14 Jan 2018 ]. http://www.ych.pref.yamanashi.jp/kitabyo/pdf/BPRSmanual(ver.1.1)R1. pdf\#search=\%27BPRS+manual\%2C+Japanease+\%28ver.1.1\%29\%27.

25. Emery CA, Barlow KM, Brooks BL, Max JE, Villavicencio-Requis A, Gnanakumar V, et al. A systematic review of psychiatric, psychological, and behavioural outcomes following mild traumatic brain injury in children and adolescents. Can J Psychiatr. 2016;61:259-69. https://doi.org/10.1177/ 0706743716643741.

26. Bosco FM, Parola A, Sacco K, Zettin M, Angeleri R. Communicativepragmatic disorders in traumatic brain injury: the role of theory of mind and executive functions. Brain Lang. 2017;168:73-83. https://doi.org/10. 1016/j.bandl.2017.01.007.

27. Ilie G, Cusimano MD, Li W. Prosodic processing post traumatic brain injury a systematic review. Syst Rev. 2017:6:1. https://doi.org/10.1186/s13643-0160385-3.

28. Malec JF, Hammond FM. The minimal clinically important difference for the Rasch neuropsychiatric inventory irritability and aggression scale for traumatic brain injury. Arch Phys Med Rehabil. 2017; https://doi.org/10.1016/ j.apmr.2017.06.038.

29. Nguyen S, McKay A, Wong D, Rajaratnam SM, Spitz G, Williams G, et al. Cognitive behavior therapy to treat sleep disturbance and fatigue after traumatic brain injury: a pilot randomized controlled trial. Arch Phys Med Rehabil. 2017:98:1508-17. https://doi.org/10.1016/j.apmr.2017.02.031.

30. McCormack HM, Horne DJ, Sheather S. Clinical applications of visual analogue scales: a critical review. Psychol Med. 1988;18:1007-19.

31. Bieri D, Reeve RA, Champion GD, Addicoat L, Ziegler JB. The faces pain scale for the self-assessment of the severity of pain experienced by children: development, initial validation, and preliminary investigation for ratio scale properties. Pain. 1990;41:139-50.

32. Laureys S, Owen AM, Schiff ND. Brain function in coma, vegetative state, and related disorders. Lancet Neurol. 2004;3:537-46.

33. Selwyn R, Hockenbury N, Jaiswal S, Mathur S, Armstrong RC, Byrnes KR. Mild traumatic brain injury results in depressed cerebral glucose uptake: an (18)FDG PET study. J Neurotrauma. 2013;30:1943-53. https://doi.org/10.1089/ neu.2013.2928.

34. Bodart O, Gosseries O, Wannez S, Thibaut A, Annen J, Boly M, et al. Measures of metabolism and complexity in the brain of patients with disorders of consciousness. Neuroimage Clin. 2017:14:354-62. https://doi. org/10.1016/j.nicl.2017.02.002

35. Su L, Cai Y, Xu Y, Dutt A, Shi S, Bramon E. Cerebral metabolism in major depressive disorder: a voxel-based meta-analysis of positron emission tomography studies. BMC Psychiatry. 2014;14:321. https://doi.org/10.1186/ s12888-014-0321-9.

36. García-Panach J, Lull N, Lull JJ, Ferri J, Martínez C, Sopena P, et al. A voxelbased analysis of FDG-PET in traumatic brain injury : regional metabolism 
and relationship between the thalamus and cortical areas. J Neurotrauma. 2011;28:1707-17. https://doi.org/10.1089/neu.2011.1851.

37. Munivenkatappa A, Devi BI, Shukla DP, Rajeswaran J. Role of the thalamus in natural recovery of cognitive impairment in patients with mild traumatic brain injury. Brain Inj. 2016;30:388-92.

38. Banks SD, Coronado RA, Clemons LR, Abraham CM, Pruthi S, Conrad BN, et al. Thalamic functional connectivity in mild traumatic brain injury: longitudinal associations with patient-reported outcomes and neuropsychological tests. Arch Phys Med Rehabil. 2016;97:1254-61. https://doi.org/10.1016/j.apmr.2016.03.013.

39. Hogrefe K, Rein R, Skomroch H, Lausberg H. Co-speech hand movements during narrations: what is the impact of right vs. left hemisphere brain damage? Neuropsychologia. 2016;93:176-88. https://doi.org/10.1016/j. neuropsychologia.2016.10.015.

40. Roxo MR, Franceschini PR, Zubaran C, Kleber FD, Sander JW. The limbic system conception and its historical evolution. Sci World JScientific World Journal. 2011;11:2428-41. https://doi.org/10.1100/2011/157150.

41. LeDoux JE. Emotion circuit in the brain. Annu Rev Neurosci. 2000;23:155-84.

42. Katherine HT, Robin AH. Neuroanatomy for the psychiatrist. Part 2. Chapter 5. : Robert EH, Stuart CY, Glen OG, editors. American psychiatric publishing textbook of psychiatry 5th edition: American psychiatric association publishing, Inc. (Washington, DC; London, England); 2008. p. 157-89.

43. Bubb EJ, Kinnavane L, Aggleton JP. Hippocampal - diencephalic - cingulate networks for memory and emotion: aAn anatomical guide. Brain Neurosci Adv. 2017;4:1. https://doi.org/10.1177/2398212817723443.

44. De Crescenzo F, Ciliberto M, Menghini D, Treglia G, Ebmeier KP, Janiri L. Is 18F-FDG-PET suitable to predict clinical response to the treatment of geriatric depression? A systematic review of PET studies. Aging Ment HealthAging Ment Health. 2017;21:889-94. https://doi.org/10.1080/ 13607863.2016.1247413.

45. Kang EH, Park JE, Lee KH, Cho YS, Kim JJ, Yu BH. Regional brain metabolism and treatment response in panic disorder patients: an [18F]FDG-PET study. NeuropsychobiologyNeuropsychobiology. 2012;66:106-11. https://doi.org/ $10.1159 / 000337740$.

46. Milak MS, Parsey RV, Lee L, Oquendo MA, Olvet DM, Eipper F, et al. Pretreatment regional brain glucose uptake in the midbrain on PET may predict remission from a major depressive episode after three months of treatment. Psychiatry ResPsychiatry Res. 2009;173:63-70. https://doi.org/10. 1016/.jpscychresns.2008.09.004

\section{Ready to submit your research? Choose BMC and benefit from:}

- fast, convenient online submission

- thorough peer review by experienced researchers in your field

- rapid publication on acceptance

- support for research data, including large and complex data types

- gold Open Access which fosters wider collaboration and increased citations - maximum visibility for your research: over $100 \mathrm{M}$ website views per year

At BMC, research is always in progress.

Learn more biomedcentral.com/submissions 